\title{
PENGARUH KOMUNIKASI TENAGA FARMASI DALAM UPAYA PENINGKATAN PEMAHAMAN LANSIA TERHADAP DAGUSIBU OBAT (DAPATKAN, GUNAKAN, SIMPAN, BUANG) DI DESA KOPEN KABUPATEN BOYOLALI
}

\author{
Amanda Anisawati ${ }^{1}$, Faizatul Isma ${ }^{2}$, Ilham La Tansa ${ }^{3}$, Rafidah Hanifah ${ }^{4}$, \\ Rizky Nur Diana ${ }^{5}$, Aris Prio Agus Santoso ${ }^{6}$ \\ 1,2,3,4,5,6 Universitas Duta Bangsa Surakarta \\ Email Korespondensi : 190209022@ fikes.udb.ac.id
}

\begin{abstract}
ABSTRAK
Penggunaan obat yang tidak rasional dan penyalahgunaanya merupakan masalah yang sering dijumpai pada masyarakat. Berdasarkan data survei yang diperoleh masih terdapat warga yang mendapatkan obat secara bebas tanpa pemantauan tenaga medis dan farmasi atau obat-obatan yang dibeli adalah obat dari toko kelontong, dan banyak warga di desa kopen, Boyolali yang belum mengetahui cara menggunakan obat yang sesuai, cara penyimpanan obat yang benar serta banyak di antaranya yang masih membuang obat cair dalam kemasan dan tanpa memperhatikan untuk merusak atau merobek kemasan obat. Edukasi mengenai Dagusibu obat merupakan salah satu upaya yang kami lakukan sebagai tenaga kefarmasian untuk mencegah penggunaan obat yang tidak rasional dan menjaga agar tidak terjadi penyelahgunaan obat oleh masyarakat terutama lansia di Desa kopen, Boyolali. Metode yang digunakan adalah metode intervensi preventif dan pendekatan secara kuantitatif terhadap lansia dengan menggunakan kuesioner Dagusibu yang kami buat. Berdasarkan pengisian kuesioner sebelum dilakukan sosialisasi didapatkan hasil 73\% lansia yang belum paham, 18\% lansia yang sedikit paham dan $9 \%$ lansia yang didampingi wali yang sudah paham. pemahaman mengenai Dagusibu obat oleh lansia di Desa Kopen, Boyolali dikategorikan belum paham. Maka perlu diadakan sosialisasi untuk meningkatkan pemahaman lansia dan juga warga di Desa kopen, Boyolali. Setelah dilakukan sosialisasi, didapatkan hasil kuesioner $27 \%$ masih belum paham, 64\% sudah paham dan juga $9 \%$ adalah lansia yang didampingi wali dalam penggunaan obat. Kesimpulan dari penelitian ini adalah peran tenaga farmasi memegang peranan yang sangat penting dalam menyampaikan informasi dan edukasi dalam peningkatan pemahaman lansia dan warga di Desa kopen, Boyolali.
\end{abstract}

Kata kunci : Komunikasi, Tenaga farmasi, Pemahaman lansia, Dagusibu, Obat. 


\title{
THE EFFECT OF PHARMACEUTICAL COMMUNICATIONS IN EFFORTS TO IMPROVE THE UNDERSTANDING OF THE LANDS OF DRUG DAGUSIBU (GET, USE, SAVE, DISPOSE) IN KOPEN VILLAGE, BOYOLALI DISTRICT
}

\begin{abstract}
Irrational use of drugs and their abusers is a problem that is often found in society. Based on the survey data obtained, there are still residents who get drugs freely without monitoring medical and pharmaceutical personnel or the drugs purchased are medicines from grocery stores, and many residents in Kopen village, Boyolali, do not know how to use appropriate drugs and how to store them. The correct medicine and many of them are still throwing away liquid medicine in the package and without paying attention to damage the medicine package. Education about the drug Dagusibu is one of the efforts we do as pharmaceutical personnel to prevent irrational drug use and to prevent drug abuse by the community, especially the elderly in Kopen Village, Boyolali. The method used is a preventive intervention method and a quantitative approach to the elderly using the Dagusibu questionnaire that we created. Based on filling out the questionnaire before we do the socilization, it was found that $73 \%$ of the elderly who do not understand, $18 \%$ of the elderly who have little understanding and $7 \%$ of the elderly who are accompanied by a guardian who already understands. The understanding of Dagusibu drugs by the elderly in the Village Kopen, Boyolali categorized't get it. It needs to be held socialization to improve the understanding of the elderly and also residents in the Village kopen, Boyolali. After socialization, the obtained results of the questionnaire $27 \%$ still do not understand, 64\% already understand and also 9\% are elderly, accompanied by a guardian in the use of the drug. The conclusion of this research is the role of pharmaceutical personnel hold a very important role in conveying information and education in an improved understanding of the elderly and residents in the Village kopen, Boyolali.
\end{abstract}

Keywords: Communication, pharmaceutical technical personnel Understanding of the elderly, Dagusibu, Medicine

\section{PENDAHULUAN}

Kesehatan merupakan salah satu indikator tingkat kesejahteraan manusia sehingga senantiasa menjadi prioritas dalam pembangunan nasional suatu bangsa. Tujuan dari pembangunan nasional khususnya bidang kesehatan adalah tercapainya derajat kesehatan masyarakat yang optimal, derajat kesehatan yang tinggi akan meningkatkan produktivitas dan 
memperkuat daya saing bangsa yang semakin ketat. Adapun tempat yang digunakan untuk menyelenggarakannya disebut sarana kesehatan. Sarana kesehatan berfungsi untuk melakukan upaya kesehatan dasar atau upaya kesehatan rujukan dan atau upaya kesehatan penunjang. Salah satu sarana kesehatan yang berperan dalam mewujudkan peningkatan derajat kesehatan bagi masyarakat adalah apotek, termasuk didalamnya pekerjaan kefarmasian yang dilakukan oleh apoteker dan tenaga teknis kefarmasian

Pelayanan kefarmasian di apotek adalah suatu pelayanan langsung dan bertanggung jawab kepada pasien yang berkaitan dengan sediaan farmasi dengan maksud mencapai hasil yang pasti untuk meningkatkan mutu kehidupan pasien (Permenkes No. 73 tahun 2016). Pengaturan Standar Pelayanan Kefarmasian di Apotek bertujuan untuk meningkatkan mutu pelayanan kefarmasian, menjamin kepastian hukum bagi tenaga kefarmasian, dan melindungi pasien dan masyarakat dari penggunaan obat yang tidak rasional dalam rangka kesehatan pasien. Obat adalah sediaan atau paduan-paduan yang siap digunakan untuk mempengaruhi atau menyelidiki secara fisiologi atau keadaan patologi dalam rangka penetapan diagnosa, pencegahan, penyembuhan, pemulihan, peningkatan kesehatan dan kontrasepsi (Permenkes No. 917 tahun 1993).

Obat merupakan kimia yang digunakan untuk mencegah, mengurangi, menghilangkan, atau menyembuhkan seseorang dari penyakit yang diderita. Saat ini obat yang telah ditemukan sejak berabad-abad lalu menjadi suatu kebutuhan yang tidak bisa ditinggalkan oleh masyarakat. Bahkan setiap orang pasti pernah mengonsumsi obat. Baik obat luar maupun obat dalam. Penggunaan obat yang aman dan rasional adalah terpenuhinya tepat pasien, tepat indikasi, tepat dosis, tepat waktu pemberian dan tepat informasi. Secara singkat pemakaian atau peresepan suatu obat dikatakan tidak rasional apabila kemungkinan untuk memberikan manfaat kecil atau tidak sama sekali atau kemungkinan manfaatnya tidak sebanding dengan kemungkinan efek samping atau biayanya (Hapsari, 2011).

Dagusibu merupakan program Gerakan Keluarga Sadar Obat (GKSO) yang diprakarsai oleh Ikatan Apoteker Indonesia dalam mencapai pemahaman dan kesadaran masyarakat terhadap penggunaan obat dengan benar. Dagusibu terdiri dari Dapatkan, Gunakan, Simpan, dan Buang Obat. (PP IAI, 2014). Adanya gerakan tersebut karena masih banyak masalah yang terkait penggunaan obat yang terjadi di masyarakat. Hal ini terlihat pada penggunaan obat yang tidak rasional. Menurut Peraturan Pemerintah Nomor 51 tahun 2009, fasilitas pelayanan kefarmasian yaitu Apotek, Instalasi Rumah Sakit, klinik, toko obat atau praktek bersama. Pada kenyataannya masih ada masyarakat yang mendapatkan obat dari orang lain sebesar $1,7 \%$, tenaga kesehatan $23,4 \%$ dan penjual obat tradisional keliling 1,3\% (Riskesdas, 2013). Obat obatan yang diperoleh bukan dari fasilitas pelayann kefarmasian dapat menjadi 
peluang masuknya obat-obat palsu. Untuk menjamin keefektifan suatu obat, perlu sistem penyimpanan yang baik dan benar.

Sedangkan untuk masyarakat Indonesia sendiri masih kurang memahami bagaimana obat tersebut disimpan dan digunakan karena kurangnya informasi yang seharusnya didapatkan (Gitawati, 2014) kesalahan dalam menyimpan obat akan mempengaruhi kondisi zat aktif tersebut. Pada saat ini, masyarakat masih sering salah dalam hal mendapatkan, menggunakan, menyimpan dan membuang obat dengan benar. Apabila masyarakat tidak tahu tentang dagusibu tersebut dapat menyebabkan terjadinya hal yang tidak diinginkan dalam pengobatan seperti obat yang tidak bisa didapatkan masyarakat, obat yang salah cara penggunaannya, obat yang tidak disimpan secara benar dan pembuangan obat secara sembarangan. Hal yang tidak diinginkan tersebut tentu saja dapat merugikan bagi masyarakat saat menggunakan obat.

\section{Rumusan Masalah}

Perumusan masalah dalam penelitian ini adalah sebagai berikut :

1. Bagaimana peran tenaga farmasi dalam upaya peningkatan pemahaman lansia terhadap pentingnya Dagusibu Obat?

2. Bagaimana tingkat pemahaman lansia desa Teras mengenai penerapan Dagusibu Obat?

\section{METODE PENELITIAN}

\section{Tempat dan Waktu Penelitian}

Penelitian dan pengambilan sampel dilakukan di Posyandu Lansia desa Kopen, Teras, Boyolali. Penelitian ini dilaksanakan pada tanggal 29 Maret 2021. Dengan penelitian ini, diharapkan akan memberikan suatu informasi kepada masyarakat desa terkait informasi tentang Dagusibu dan manfaat untuk meningkatkan kemampuan komunikasi efektif tenaga kefarmasian.

\section{Populasi}

Populasi dalam penelitian ini yaitu semua lansia di Posyandu Lansia, desa Kopen, Teras, Boyolali, Jawa Tengah dengan rentang usia $\geq 40$ tahun.

\section{Sampel}

Pengambilan sampel dalam penelitian ini menggunakan teknik non probability sampling yaitu quota sampling. Quota sampling dipilih karena penelitian dilakukan jauh hari sebelum masa pendaftaran dilakukan, maka populasinya secara kesuluruhan bersifat tak terhingga (hanya ada "satu" populasi, tidak terdiri atas "dua subpopulasi"), karena yang mendaftar belum ada. Maka penelitian ini mengambil sampel sebanyak 11 responden dikarenakan sampel tersebut diperkirakan dapat mencerminkan populasi sebagai sampel penelitian.

\section{Rancangan Penelitian}

Penelitian ini menggunakan metode survey kuantitatif. Metode ini merupakan salah satu teknik pengumpulan data dengan mengumpulan data melalui pembagian 
kuesioner dan dengan pendekatan deskriptif dapat mengetahui bahwa informasi yang disampaikan akan diperoleh responden saat penetian dilaksanakan.

\section{Teknik Pengumpulan Data}

Pengumpulan data dilakukan dengan menggunakan serangkaian instrumen penelitian berupa tes/kuesioner. Data yang terkumpul kemudian dikonversikan menggunakan kategori/kriteria yang sudah ditetapkan sebelumnya. Teknik yang kami lakukan dengan penyuluhan dan dilanjutkan dengan pendekatan individual untuk

\section{HASIL DAN PEMBAHASAN}

Komunikasi tenaga kefarmasian memegang peran yang penting dalam meningkatkan pemahaman masyarakat terhadap informasi dan edukasi tentang obat-obatan, salah satunya tentang Dagusibu obat. Kegiatan penyuluhan mengenai DAGUSIBU (DApatkan, GUnakan, SImpan, BUang) (Kemenkes RI, 2013)

\section{a. Dapatkan}

Mendapatkan obat yang benar dilakukan dengan memperhatikan penggolongan obat, informasi pada kemasan, dan kadaluarsa obat. Masyarakat diharapkan memperoleh obat obatan dari sarana kesehatan yang mempunyai lisensi/legal. Contohnya belilah obat dari apotek yang mempunyai nomor SIA (Surat Izin Apotek), ini bisa dilihat di palang apotek tersebut. jika membeli obat di toko obat, lihat pula izin toko obat tersebut. Pastikan juga klinik dokter pengisian kuesioner mengenai penerapan Dagusibu obat kepada lansia.

\section{Analisis Data}

Teknik analisis data dalam penelitian ini menggunakan teknik analisis kuantitatif, dengan membuat analisa dari perolehan hasil kuesioner dari para responden sebelum dibuat laporan hasil penelitian. Adapun analisis kuantitatif dalam penelitian ini digunakan untuk menjawab bagaimana pentingnya peran tenaga farmasi dalam upaya peningkatan pemahaman lansia terhadap pentingnya Dagusibu Obat

yang didatangi memiliki izin. Hal yang terpenting adalah belilah obat di sarana kesehatan yang mempunyai izin. Cara untuk mengetahui bahwa sarana kesehatan tersebut memiliki izin :

1. Melihat nomor izin seperti SIA di palang apotek/toko obat/klinik tersebut.

2. Bertanya pada petugas apotek.

3. Jika tidak ditemukan nomor izin tersebut, lebih baik beli obat langsung di apotek. Karena, pendirian apotek sudah memiliki regulasi tersendiri, sehingga pendirian apotek ilegal sangat tidak mungkin terjadi.

b. Gunakan

Menggunakan obat dengan benar sesuai petunjuk pada kemasan obat. Kita dapat menemukan obat dalam jenis dan cara penggunaan yang berbeda-beda. Seperti kapsul, 
tablet, sirup, suspensi, salep, krim, dan lain-lain. Menurut cara penggunaannya ada obat tetes telinga, hidung, salep mata, suppositoria, dan lain-lain. Dalam penggunaan obat ini, masyarakat harus diedukasi berdasarkan jenis obat apa yang ia terima dan bagaimana cara menggunakannya. Oleh karena itu, peran apoteker sangat dibutuhkan di sini. Jangan sampai obat yang seharusnya dimasukkan lewat dubur malah ditelan oleh pasien. Atau pasien malah tidak mengetahui bagaimana cara meneteskan obat tetes hidung dengan baik dan benar.

Selain itu ada suatu hal penting yang saat ini masyarakat awam beranggapan bahwa ketika sakit batuk, pilek, dan demam, perlu mengonsumsi antibiotik. Padahal yang benar adalah jangan terburuburu dalam menggunakan antibiotik. Setelah antibiotik mulai dikonsumsi, maka hal yang harus diperhatikan adalah antibiotik harus habis. Biasanya sebanyak 10 tablet antibiotik habis dalam waktu tiga hari jika diminum setiap sehari tiga kali.

c. Simpan

Menyimpan obat dengan benar sesuai petunjuk pada kemasan. Obat disimpan dalam kondisi tertentu. Pada suhu tertentu dan di tempat yang kering. Sifat obat yang mudah terdegradasi/berubah menjadi senyawa kimia lain dapat menyebabkan obat tidak stabil dalam kondisi tertentu. Biasaya kita temukan kalimat "Jauhkan dari sinar matahari langsung. Simpan pada suhu kamar" dalam sebuah kemasan obat. Seperti suntik insulin untuk pasien diabetes, obat ini harus disimpan dalam lemari pendingin, sementara tablet biasa, tidak masalah jika disimpan pada suhu kamar. Oleh karena itu, lebih baik simpan obat pada kotak obat dan jauhkan kotak itu dari jangkauan anak-anak serta sinar matahari langsung dan simpanlah ditempat yang kering.

d. Buang

Setelah masa kadaluarsa obat berakhir, maka hendaklah kita membuang obat pada tempatnya. Tempat pembuangan obat sesuai dengan jenis sediaan obat tersebut. Untuk tablet dan sejenisnya (padat), maka obat tersebut dihancurkan dan buang ke tanah yang tidak ditumbuhi tanaman. Untuk cairan, lebih baik dibuang ke tanah juga, karena jika dibuang ke dalam air dapat menyebabkan makhluk hidup di dalam air mati atau terkontaminasi dengan zat kimia obat. Plastik obat, dibuang pada tempat sampah. Membuang obat juga harus bersamaan dengan kemasannya setelah label dilepas, termasuk membuang obat antibiotik.

Penyuluhan ini bertujuan untuk memberikan edukasi dan informasi kepada lansia serta menumbuhkan kesadaran bahwa penggunaan obat tidak boleh sembarangan mulai dari cara mendapatkannya, cara menggunakan, cara menyimpan hingga cara 
membuangnya. Penyuluhan ini dirasa penting mengingat kurangnya informasi edukasi mengenai Dagusibu pada lansia di desa Kopen, Teras, Boyolali. Penaganan obat yang tepat dibutuhkan agar penggunaan obat secara rasional tetap terjaga. Sebelum kegiatan dilaksanakan, hal pertama yang dilakukan adalah koordinasi dengan pihak Posyandu Lansia desa Kopen, Teras, Boyolali. Pihak Posyandu lansia mendukung penuh adanya kegiatan penyuluhan Dagusibu terhadap lansia karena pihak Posyandu merasa minimnya informasi dan edukasi yang diberikan terhadap lansia mengenai Dagusibu.
Penyuluhan dilakukan pada tanggal 29 Maret 2021 berlokasi di salah satu rumah warga setempat pada saat diadakannya pemeriksaan Posyandu lansia dari puskesmas di desa Kopen, Teras, Boyolali. Kegiatan penyuluhan dimulai dengan senam bersama dengan para lansia dilanjutkan penyuluhan mengenai Dagusibu, pada saat kami melakukan penyuluhan peserta sangat antusias dan menanyakan beberapa hal terkait dengan penggunaan obat yang mereka lakukan sehari-hari, kemudian diadakan cek kesehatan yang dilakukan oleh bidan dari puskesmas setempat, dan yang terakhir kami melakukan sesi tanya jawab mengenai Dagusibu
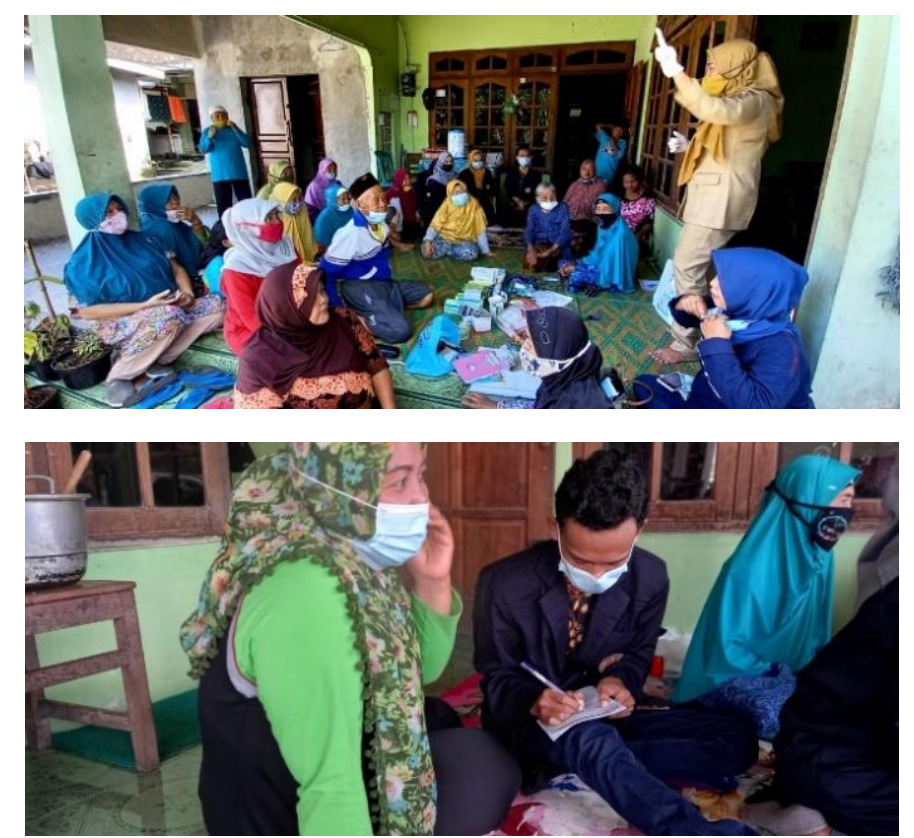


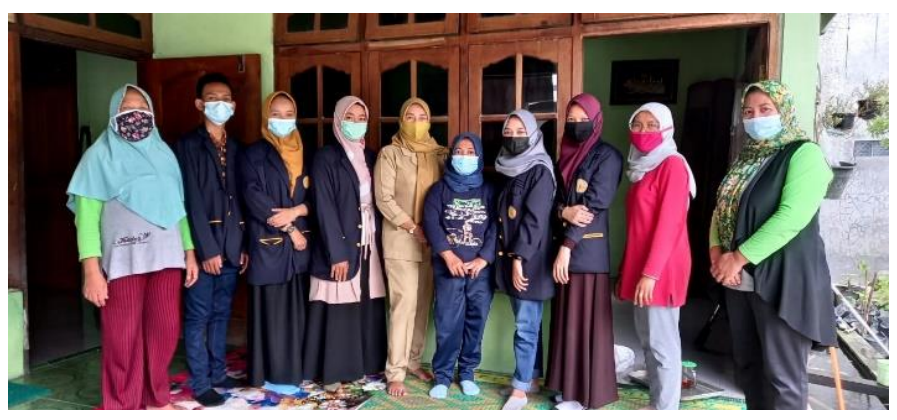

Gambar 1. Kegiatan penelitian dan penyuluhan

Dagusibu posyandu lansia

Dari penelitian dan penyuluhan yang kami lakukan di desa Kopen, Teras,
Boyolali maka diperoleh data sebagai berikut

Tabel 1. Data warga lansia dan penerapan Dagusibu

\begin{tabular}{llccc}
\hline No. & \multicolumn{1}{c}{ Nama } & Usia & $\begin{array}{c}\text { Persediaan obat/obat } \\
\text { yang dikonsumsi }\end{array}$ & Indeks \\
\hline 1. & Ny. Watini & 66 & Jamu herbal & B \\
2. & Ny. Sri Yani & 69 & Antasida & B \\
3. & Ny. Sri Sudarti & 70 & Tetes mata & B \\
4. & Ny.Ngartinem & 77 & Tetes mata & B \\
5. & Ny. Sri Partini & 60 & Salep kulit & B \\
6. & Ny. Mujimah & 59 & Antasida, obat & K \\
7. & Ny. Sri Mulyani & 78 & kolestrol & Antasida \\
8. & Ny. Sri Wahyuni & 40 & Analgetik & K \\
9. & Ny. Marsih & 52 & Vitamin & B \\
10. & Ny. Pariyem & 60 & Antasida & B \\
11. & Ny. Sukarsi & 94 & Obat asam urat & S \\
\hline
\end{tabular}

\section{Keterangan:}

B: belum sesuai dalam penerapan Dagusibu K: masih kurang sesuai penerapan Dagusibu S: sudah sesuai menerapkan Dagusibu. 
Diagram 1. Presentasi pemahaman warga dan lansia mengenai Dagusibu sebelum sosialisasi

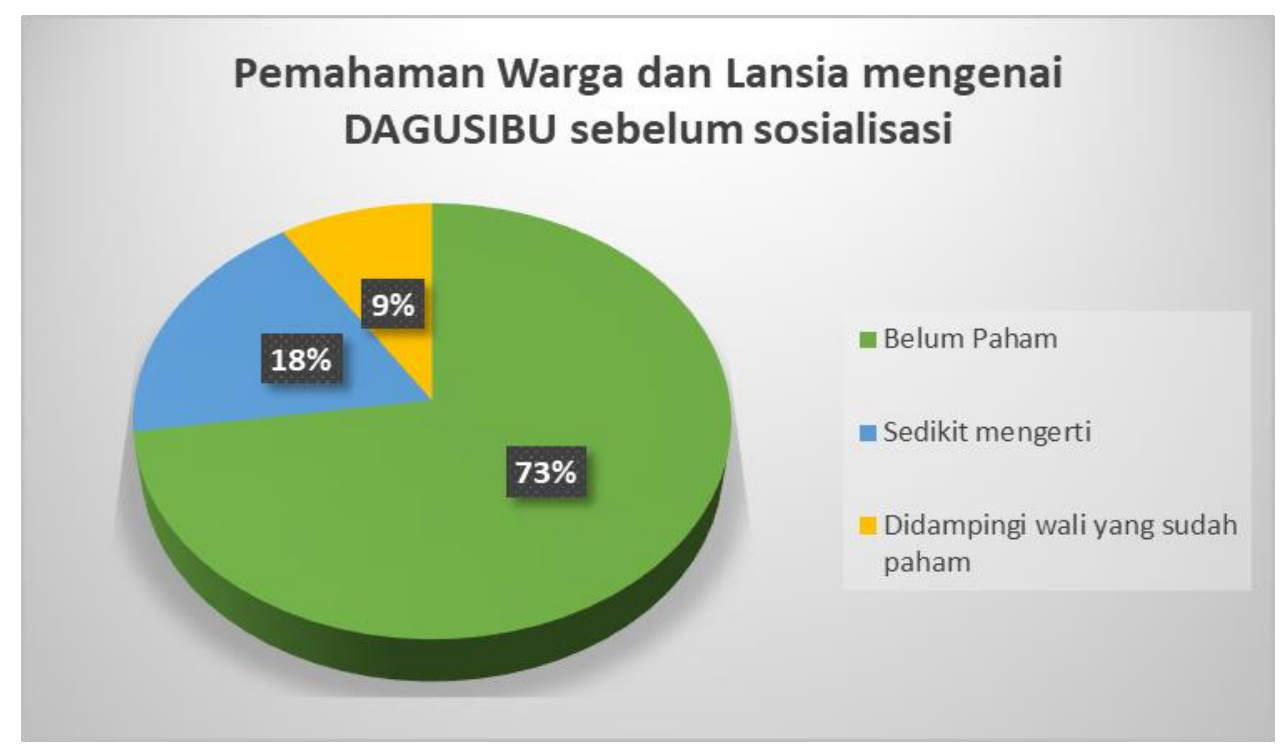

Diagram 2. Presentasi pemahaman warga dan lansia mengenai Dagusibu sesudah sosialisasi

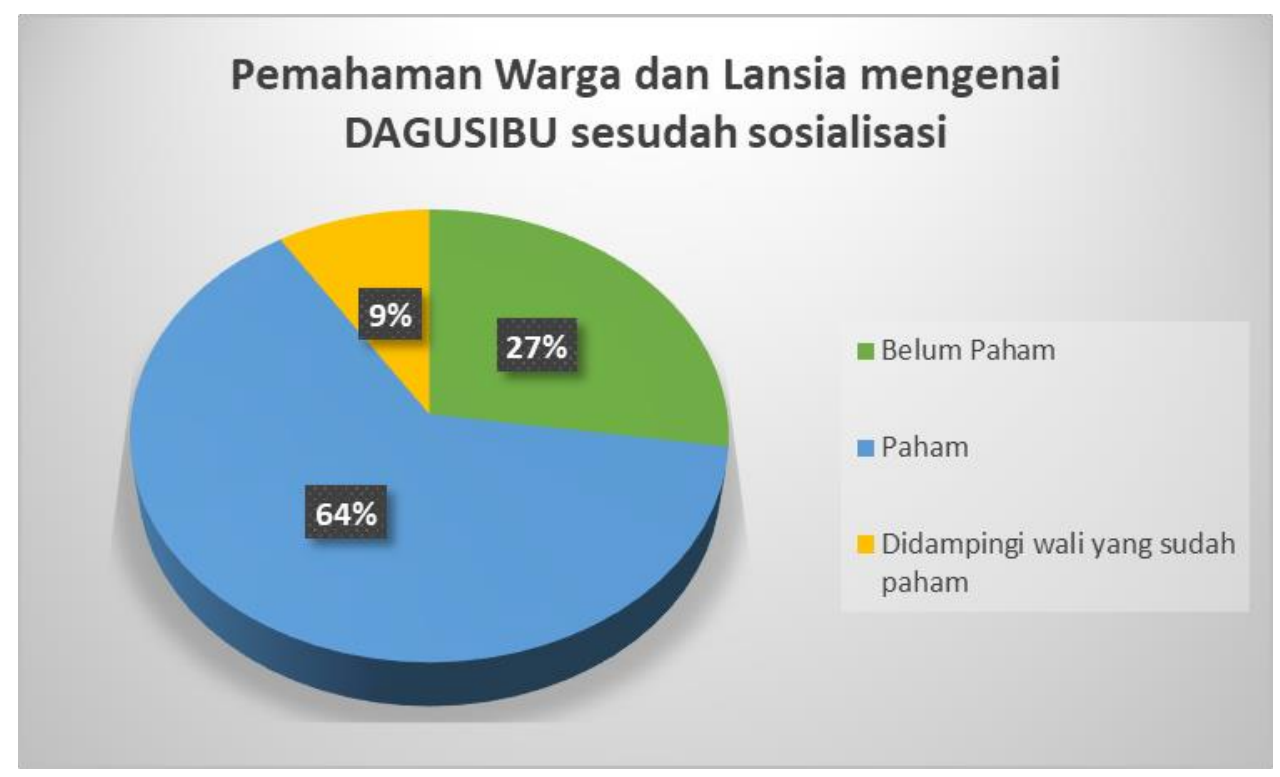


Berdasarkan hasil kuesioner
sebelum sosialisasi diperoleh $73 \%$ lansia yang belum paham mengenai Dagusibu obat, $18 \%$ lansia yang sedikit mengerti dan 9\% lansia yang didampingi wali yang sudah paham, dapat dikategorikan bahwa warga dan juga lansia di desa Kopen, Boyolali belum paham mengenai pengelolaan obat dengan Dagusibu serta mereka masih mendapatkan obat secara bebas tanpa pemantauan tenaga medis dan farmasi atau obat-obatan yang dibeli adalah obat dari toko kelontong, banyak warga yang belum mengetahui cara menggunakan obat yang sesuai, cara penyimpanan obat yang benar serta banyak di antaranya yang masih membuang obat cair masih dalam kemasan dan tanpa memperhatikan untuk merusak atau merobek kemasan obat.

Pada saat kami melakukan tanya jawab banyak warga yang kurang paham dan bahkan belum mengetahui cara penggunaan obat luar dan juga cara penyimpanan obat luar. Contoh permasalahannya adalah dalam menggunakan obat tetes mata dan juga salep masih banyak terdapat warga yang menyimpan obat tetes mata selama berbulan-bulan dan juga penggunaan obat tetes secara bersamaan. Terdapat pula warga yang kurang memperhatikan kebersihan tangan atau area kulit sebelum penggunaan salep. Karena obat tetes mata merupakan sediaan steril maka penyimpanan tetes mata adalah maksimal 1 bulan setelah kemasan dibuka, jika disimpan terlalu lama maka obat tetes akan terkontaminasi bakteri atau sediaan menjadi rusak. Begitu juga dengan obat-obatan lain jika disimpan dalam jangka waktu yang melebihi ketentuan maka obat akan rusak dan tidak berkhasiat.

Setelah kami melakukan sosialisasi mengenai pentingnya Dagusibu dan bagaimana penerapannya di kehidupan sehari-hari, kami mendapatkan hasil pengisian kuesioner yaitu, 27\% masih belum paham, 64\% sudah paham dan juga $9 \%$ adalah lansia yang didampingi wali dalam penggunaan obat. Melalui hasil kuesioner dan juga sosialisasi ini peran tenaga farmasi dalam menyampaikan informasi dan edukasi mengenai obat yang akan diterima oleh pasien sangatlah penting. Sebelum menyerahkan obat kepada pasien pastikan pasien menerima informasi mengenai kejelasan cara penggunaan dan penyimpanan obat, sampaikan juga bagaimana cara membuang obat atau kemasan obat dengan benar. Bila terdapat pasien lansia, anak-anak, atau pasien dengan penyandang disabilitas maka pastikan pasien mempunyai wali yang mendampinginya dalam penggunaan obat tersebut. Kejelasan penulisan etiket dan label yang disertakan dalam kemasan obat juga harus dapat dimengerti dan dipahami oleh pasien atau wali pasien. Pastikan informasi yang diberikan kepada pasien dan juga keluarga pasien dapat dimengerti sehingga penerapan Dagusibu obat dapat berjalan secara maksimal dan rasional.

Fasilitas pelayanan kesehatan setempat juga turut berperan dalam upaya peningkatan pemahaman 
masyarakat terhadap Dagusibu obat. Misalnya dengan adanya posyandu ataupun penyuluhan-penyuluhan kesehatan, tenaga kesehatan atau petugas setempat bisa memfasilitasi untuk mengadakan edukasi tentang pentingnya Dagusibu.

\section{KESIMPULAN}

Kesimpulan dari penelitian ini adalah : Berdasarkan kegiatan sebelum sosialisasi yang dilakukan, diperoleh hasil 73\% lansia yang belum paham, $18 \%$ lansia yang sedikit paham dan $9 \%$ lansia yang didampingi wali yang sudah paham. Hal ini dapat dikategorikan bahwa warga dan juga lansia di desa Kopen, Boyolali belum paham mengenai pengelolaan obat dengan Dagusibu, namun setelah diadakan sosialisasi pemahaman warga di desa Kopen, Boyolali mengalami peningkatan yaitu menjadi $27 \%$ masih belum paham, 64\% sudah paham dan juga $9 \%$ adalah lansia yang didampingi wali dalam penggunaan obat. Hal tersebut membuktikan bahwa tenaga kefarmasian sangat berperan penting dalam peningkatan pemahaman lansia terhadap pentingnya Dagusibu Obat, karena tenaga farmasi memiliki wewenang dan kewajban dalam penyampaian informasi dan edukasi obat tersebut agar penggunaan dikalangan masyrakat umum tetap normal. Tentunya disertai dengan dukungan dari fasilitas pelayanan kesehatan setempat yang juga harus berperan dalam melakukan penyuluhan kepada warga

\section{UCAPAN TERIMAKASIH}

Pada kesempatan ini, peneliti ingin mengucapkan terima kasih kepada berbagai pihak yang telah membantu terwujudnya penelitian ini :

1. Pihak Posyandu Lansia di Desa Kopen, Kabupaten Boyolali

2. Dosen Komunikasi Farmasi Universitas Duta Bangsa Surakarta selaku Pembimbing

\section{DAFTAR PUSTAKA}

Djuria, R. (2015). Penyuluhan Tata Laksana Pelayanan Informasi Obat (PIO) "DAGUBISU". Laporan Kegiatan Pengabdian Masyarakat. Jurusan Farmasi. Poltekkes Kemenkes RI Pangkalpinang. Bangka Belitung.

Hajrin, W., Subaidah, W. A., \& Juliantoni, Y. (2020). Sosialisasi DAGUSIBU Untuk Meningkatkan Rasionalitas Penggunaan Obat Bagi Masyarakat Kerandangan Desa Senggigi. Jurnal Pengabdian Magister Pendidikan IPA, 3(2).

Kemenkes RI. (2013). Riset Kesehatan Dasar; RISKESDAS. Jakarta: Balitbang Kemenkes RI

Liliweri, Alo. (2008). Dasar-dasar Komunikasi Kesehatan. Jakarta : Pustaka Pelajar

Mazziyah, N. (2015). Penyuluhan Penggunaan Obat Yang Benar (DAGUSIBU ) di Padukuhan Bakalan, Mlati, Sleman, Yogyakarta. Laporan Kegiatan Pengabdian Masyarakat. 
Program Studi Farmasi. Fakultas

Kedokteran dan Ilmu Kesehatan.

Universitas Muhammadiyah

Yogyakarta

Mukti, A. W., \& Mayzika, N. A. (2020). Profil Perilaku dan Pengetahuan Warga Kelurahan Dukuh Menanggal Surabaya tentang

DAGUSIBU. Dedication:

Jurnal Pengabdian Masyarakat, 4(1), 1-10.

Notoatmodjo, S. (2010). Metodologi Penelitian Kesehatan. Jakarta: PT.Rineka Cipta

Santoso, Aris. P. A. dan Tatiana Siska Wardani. (2020). Etika Profesi
Kefarmasian dan Hukum

Kesehatan. Jakarta: Trans Info Media.

Santoso, Aris. P. A. (2020). Hukum Kesehatan. Yogyakarta: Pustaka Baru

Santoso, Aris. P. A. dan Tatiana Siska Wardani. (2021). Pengantar Komunikasi Kesehatan. Jakarta: Trans Info Media.

Sari, dkk. (2015). Kurangnya Pengetahuan Masyarakat Mengenai DAGUSIBU Makalah Bahasa Indonesia. Fakultas Farmasi. Universitas Airlangga. Surabaya. 